\title{
МЕХАНИЗМЫ ИНТЕГРАЦИИ ВУЗОВСКОЙ НАУКИ В НАЦИОНАЛЬНУЮ ИННОВАЦИОННУЮ СИСТЕМУ И МИРОВОЙ ИННОВАЦИОННЫЙ ПРОЦЕСС
}

\section{MECHANISMS FOR INTEGRATING UNIVERSITY SCIENCE INTO THE NATIONAL INNOVATION SYSTEM AND THE WORLD INNOVATION PROCESS \\ O. Kozhukalova S. Demina}

Summary. The article is devoted to the study of the mechanisms of integration of university science into the national innovation system and the world innovation process. The author outlines the relevance and significance of the topic of research. As a result of terminological analysis, the author's definition of the definition "integration of university science into the national innovation system and the world innovation process" is distinguished. The classification of models of innovative specialization of the university in the process of integration into the national innovation system and the world innovation process is presented depending on the structure of interaction between the educational organization and the governing community of the corresponding level. Recommendations on optimization of mechanisms of integration of university science into the national innovation system and the world innovation process are presented.

Keywords: integration of university science, national innovation system, world innovation process, national project, scientific and educational structure.

\author{
Кожукалова Оксана Юрьевна \\ К.э.н., дочент, Московский педагогический \\ государственный университет \\ o.kozhukalova@mpgu.su \\ Демина Светлана Александровна \\ К.э.н., дочент, Московский педагогический \\ государственный университет \\ sa.demina@mpgu.su
}

Аннотация. Статья посвящена рассмотрению механизмов интеграции вузовской науки в национальную инновационную систему и мировой инновационный процесс. Автором обозначена актуальность и значимость темы исследования. В результате терминологического анализа выделяется авторское определение дефиниции «интеграция вузовской науки в национальную инновационную систему и мировой инновационный процесс». Представлена классификация моделей инновационной специализации вуза на этапе интеграции в национальную инновационную систему и мировой инновационный процесс в зависимости от структуры взаимодействия образовательной организации и руководящего сообщества соответствующего уровня. Представлены рекомендации по оптимизации механизмов интеграции вузовской науки в национальную инновационную систему и мировой инновационный процесс.

Ключевые слова: интеграция вузовской науки, национальная инновационная система, мировой инновационный процесс, национальный проект, научно-образовательная структура.
H еоспорим тот факт, что перед Россией сегодня поставлены весьма амбициозные цели по осуществлению прорыва в области научно-технологического и социально-экономического развития, а также улучшения качества жизни населения, создания комфортных условий для жизни и ведения бизнеса, самореализации каждого человека. Ключевым инструментарием достижения данных целей является комплекс национальныхпроектов, которыйбыл инициирован Президентом РФ в 2018 г. [1] в целях реализации стратегии инновационного развития государства, что по мнению экспертов, в нашей стране де-факто делается впервые [11]. Особое место среди них занимает проект «Наука», одной из целей которого является обеспечение присутствия Российской Федерации в числе пяти ведущих стран мира, осуществляющих научные исследования, разработки, инновационную деятельность в областях, определяемых приоритетными научно-технологического развития. Первостепенная роль в достижении данной цели отводится образовательным организациям высшего образования. Доказательством этому, в частности, служит тот факт, что ключевым трендом мирового развития является стремление к созданию институций, способных к исполнению социального заказа в условиях «высшего этапа эволюции инновационного модуса экономики, где главным фактором и целью прогресса и роста становятся знания и человеческий капитал» $[12$, с. 46], т.е. экономики знаний. И именно в связи с актуализацией данного тренда, по справедливому замечанию Е.А. Беловой, существует необходимость внедрения в практику управления инновационным потенциалом российских вузов новых организационно-интеграционных механизмов $[4,5]$, которые позволят не только вывести российскую науку и образование в мировые лидеры, но и сделать 
конкурентоспособной, формулируемую с их помощью, национальную инновационную систему (далее - НИС).

Прежде чем говорить о механизмах, необходимо уточнить саму категорию «интеграция вузовской науки в национальную инновационную систему и мировой инновационный процесс». Б.А. Райзенберг под интеграцией понимает «объединение экономических субъектов, углубление их взаимодействия, развитие связей между ними» $[13$, с. 138]. В современной теории существует множество различных подходов к пониманию данного термина в разрезе модели «наука - образование», в частности, в контексте включения ее в НИС. Так, С точки зрения права $[8,9,14]$, данные процессы рассматриваются в отраслевом и межотраслевом аспектах (внутри- и межведомственном). В рамках первого интеграция представляется как «коммуникативный» процесс науки и образования в границах одной сферы государственного управления - образования. Второй - более широкий; он объясняет интеграцию с позиции охвата нескольких сфер государственного управления, так как отражает корреляцию науки, производства и образования, а также культуры, партнерства производства и образовательных организаций для оптимизации, соответственно, образовательной и научной деятельности. Не менее актуальным является подход, в рамках которого интеграция науки и образования признается иерархической структурой, организованной в рамках социально-экономической системы $[1,15,17]$. В соответствии с ним, интеграция имеет три уровня - микро-, мезо- и макро-. Интеграция науки и образования на первом уровне представляет собой взаимодействие этих составляющих в пределах одной организации или на уровне внутриведомственной интеграции, то есть речь идет о сотрудничестве научно-образовательных организаций определенной ведомственной принадлежности. Второй уровень отражает межотраслевую (межведомственную) интеграцию - коллаборативное взаимодействие научных организаций и вузов различной ведомственной принадлежности, к примеру, реализация совместных исследований государственных образовательных организаций высшего образования и научных структур РАН. Соответственно, на третьем уровне интеграция представляется как целостная система образовательно-научной деятельности в масштабе страны. В рамках темы данной статьи, будет целесообразно также сказать о четвертом - мега-уровне, на котором научно-образовательная деятельность, как результат интегративной практики осуществляется на наднациональном (например, в рамках ЕАЭС [10, с. 64]) или межнациональном уровне. Сказанное позволяет заключить, что интеграциия вузовской науки в национальную инновационную систему и мировой инновационный проиесс - это объединение имеющихся ресурсов высшей школы в целях углубления, систематизации и повышения эффек- тивности инновационного потенциала вузов, а также организация инновационной инфраструктуры на базе взаимодействия участников научной и образовательной экосистемы различного уровня для активного участия в формировании национальной инновационной системы и мирового инновационного процесса.

Международный опыт свидетельствует о том, что в качестве фундамента НИС хорошо себя зарекомендовали так называемые интегрированные научно-образовательные структуры, ориентированные на (1) актуализацию исследовательской и образовательной повестки, (2) инноватизации и трансфер технологий и (3) подготовку качественно новых специалистов, востребованных на рынке труда, в основе которых лежит принцип коллаборации. С позиции М. Вень, Г.В. Петрук [6], Л.Л. Ворошиловой [7], О.В. Чистяковой [16] и др. эффективность функционирования данных структур определяется сложившейся моделью построения инновационной системы на одном из уровней (микро-, мезо-, макро-, мега-), а также степенью заинтересованности управляющего сообщества и концентрации процессов генерации передовых производственных технологий. Так, в общем виде, модели инновационной специализации вуза в процессе интеграции в НИС и мировой инновационный процесс в зависимости от структуры взаимодействия образовательной организации и руководящего сообщества соответствующего уровня могут быть классифицированы в рамках четырех типов: вузовская инициатива, региональная инициатива, федеральная инициатива и межнациональная (наднациональная) инициатива. В рамках первой модели структурные подразделения образовательной организации, которые реализуют инновационную политику, инновационные организации и объекты инновационной инфраструктуры выступают в роли главного инициатора и драйвера инновационной деятельности субъекта Российской Федерации, а руководящее сообщество совместно с представителями частного сектора, выстраивают вокруг образовательной организации свою инновационную деятельность. Таким образом, вуз является центральный активом механизма интеграции науки в НИС. В рамках второй и третей модели инициатором и координатором инновационной деятельности в рамках инновационной системы соответствующего уровня выступает руководящее сообщество, а вузы и предприниматели централизованно участвуют в процессе ее развития. Особенностью четвертой модели является то, что руководящие сообщества и образовательные организации двух и более государств выступают в качестве основных субъектов планирования и реализации процессов развития инновационной системы.

Практическая реализация названных моделей является одной из генеральных целей национального 
проекта «Наука» и данный процесс уже запущен. Так, в 2019 г. Правительством РФ был сформулирован инструментарий поддержки научно-образовательных центров мирового уровня на основе интеграции вузов и научных организаций и их кооперации с организациями, действующими в реальном секторе экономики [2]. Подобный формат сотрудничества позволит: усилить вовлеченность вузов и иных субъектов и отраслей в научно-технологическую повестку, сбалансировать все ресурсы (образовательные, кадровые, финансовые и пр.), снизить влияние правовых и отраслевых барьеров, в целях увеличения скорости и качества создания технологий и их трансферта в наукоемкие сектора экономики, сократить издержки взаимодействия исследователей, инженеров и технологических предпринимателей, открыть доступ к услугам, необходимым для осуществления научно-образовательной, научно-технической и инновационной деятельности, а также, как результат, развить сетевые формы организации данных видов деятельности и партнерства субъектов, их реализующих.

Однако, неоспорим тот факт, что формирование и укрепление роли вуза, как главного актива интеграции участников инновационных процессов в рамках НИС и мирового инновационного процесса, предполагает постоянный контроль и коррекцию «стратегии». В качестве мер, которые позволят своевременно и оптимально модернизировать механизмы этой интеграции, можно предложить следующие:

- во-первых, необходимо постоянное изучение и апробирование зарубежного опыта универси- тетов по освоению новых рынков высокотехнологичной продукции, в частности для реализации собственных инновационных технологий;

- во-вторых, несмотря на барьеры, созданные представителями мировой политической арены, все же целесообразно искать и налаживать каналы сотрудничества с международными институтами экономического развития в формате поиска и привлечения потенциальных инвесторов;

- в-третьих, имеет смысл развивать практику коммерциализации результатов научно-исследовательской деятельности и внедрения их в систему управления вузов, например, с помощью самостоятельной подачи заявок на привлечение инвестиций в венчурные фонды различных уровней;

- в-четвертых, важно принимать участие научных коллективов и молодых ученых отечественных вузов в национальных, наднациональных и межнациональных конкурсах на получение грантов. Следует обращать внимание на конкурсы, где организаторами, в частности, являются субъекты научно-технической экосистемы. В пример можно привести Фонд содействия развитию малых форм предприятий в научно-технической сфере (Россия, г. Москва);

- в-пятых, рекомендуется организовать меры по фасилитации административных процедур использования авторами результатов своей научно-исследовательской деятельности как нематериального актива.

\section{ЛИТЕРАТУРА}

1. Указ Президента РФ от 07.05.2018 № 204 «0 национальных целях и стратегических задачах развития Российской Федерации на период до 2024 года» // Собрание законодательства от 14.05.2018 № 20, ст. 2817

2. Постановление Правительства РФ от 30.04.2019 № 537 (ред. от 28.01.2020) «0 мерах государственной поддержки научно-образовательных центров мирового уровня на основе интеграции образовательных организаций высшего образования и научных организаций и их кооперации с организациями, действующими в реальном секторе экономики» // Собрание законодательства Российской Федерации, № 19, 13.05.2019, ст. 2294.

3. Апанасюк Л.А., Солдатов А.А. Социально-психологические условия оптимизации межкультурного взаимодействия в образовательном пространстве ВУЗа // Ученые записки РГСУ. 2017. Т. 16. № 5 (144). С. 143-150

4. Белова Е. А. Методологические основы оценки эффективности интеграции вузовской науки в национальную инновационную систему РФ // Вестник Университета (Государственный университет управления), 2017. № 5. С. 48-55

5. Белова Е. А. Формирование комплексного подхода к эффективной интеграции вузовской науки в национальную инновационную систему // Креативная экономика. 2018. Т. 12. № 6. С. 855-864. doi: 10.18334/се.12.6.39155

6. Вень М., Петрук Г. В. Наука, образование и бизнес: зарубежный и отечественный опыт интеграционного взаимодействия // АНИ: экономика и управление. 2017. № 2 (19). С. 216-219.

7. Ворошилова Л.Л. Инновации и конкурентоспособность вуза на рынке образовательных услуг // Российское предпринимательство. 2002. Т. 3. № 11. С. 76-81.

8. Вяткина Г.О., Кириченко П. Н. Правовое регулирование организации научно-исследовательской деятельности обучающихся образовательных организаций высшего образования (на примере анализа опыта субъектов Центрального федерального округа) // Вестник БГУ. 2019. № 4 (42). С. 139-149.

9. Гордеева Н.А., Пучкова М. В., Филь М. М. Правовое обеспечение интеграции науки и образования // Закон.—М.: Известия. 2006. № 4. С. $21-29$.

10. Евразийская экономическая интеграция: перспективы раз вития и стратегические задачи для России: докл. к ХХ Апр. междунар. науч. конф. по проблемам развития экономики и общества, Москва, 9-12 апр. 2019 г. / Т. В. Бордачев, К. О. Вишневский, М. К. Глазатова и др.; отв. ред. Т. А. Мешкова; Нац. исслед. ун-т «Высшая школа экономики».—- М.: Изд. дом Высшей школы экономики, 2019. - 123 с. 
11. Колин К. К. Национальные проекты в новой стратегии инновационного развития России // Интернет-журнал «Культура и безопасность». 2019. № 1. ULR: http://sec.chgik.ru/1953-2/ (дата обращения 19.07.2020)

12. Пшихачева А. А. Роль гуманитарного образования в развитии экономики // Страховое дело. 2019. № 4 (313). С. $45-49$.

13. Райзберг Б. А. Современный экономический словарь / Б. А. Райзберг, Л. Ш. Лозовский, Е. Б. Стародубцева. — 6-е изд., перераб. и доп. — М.: ИНФРА-М, 2017. - $512 \mathrm{C}$.

14. Соколова Н. А. Международное сотрудничество в сфере науки, инноваций и образования Российской Федерации со странами Европейского Союза // Lех Russica. 2018. № 12 (145). C. 48-56.

15. Тягунова Ю.В., Крикунов К. Н. Субъекты и цели интеграции науки и образования в высшей школе // Высшее образование сегодня. 2010. № 5. С. 21-26.

16. Чистякова О. В. Развитие технополисов и наукоградов как фактор активизации инновационных процессов в России // Известия БГУ. 2012 . № 2. С. 97-100.

17. Шадрин А. И. Интеграция образования и науки в регионе: вопросы теории и практики: монография / Краснояр. гос. пед. ун-т им. В. П. Астафьева.— Красноярск, 2018. - 218 c.

○ Кожукалова Оксана Юрьевна ( o.kozhukalova@mpgu.su ), Демина Светлана Александровна ( sa.demina@mpgu.su ).

Журнал «Современная наука: актуальные проблемы теории и практики»

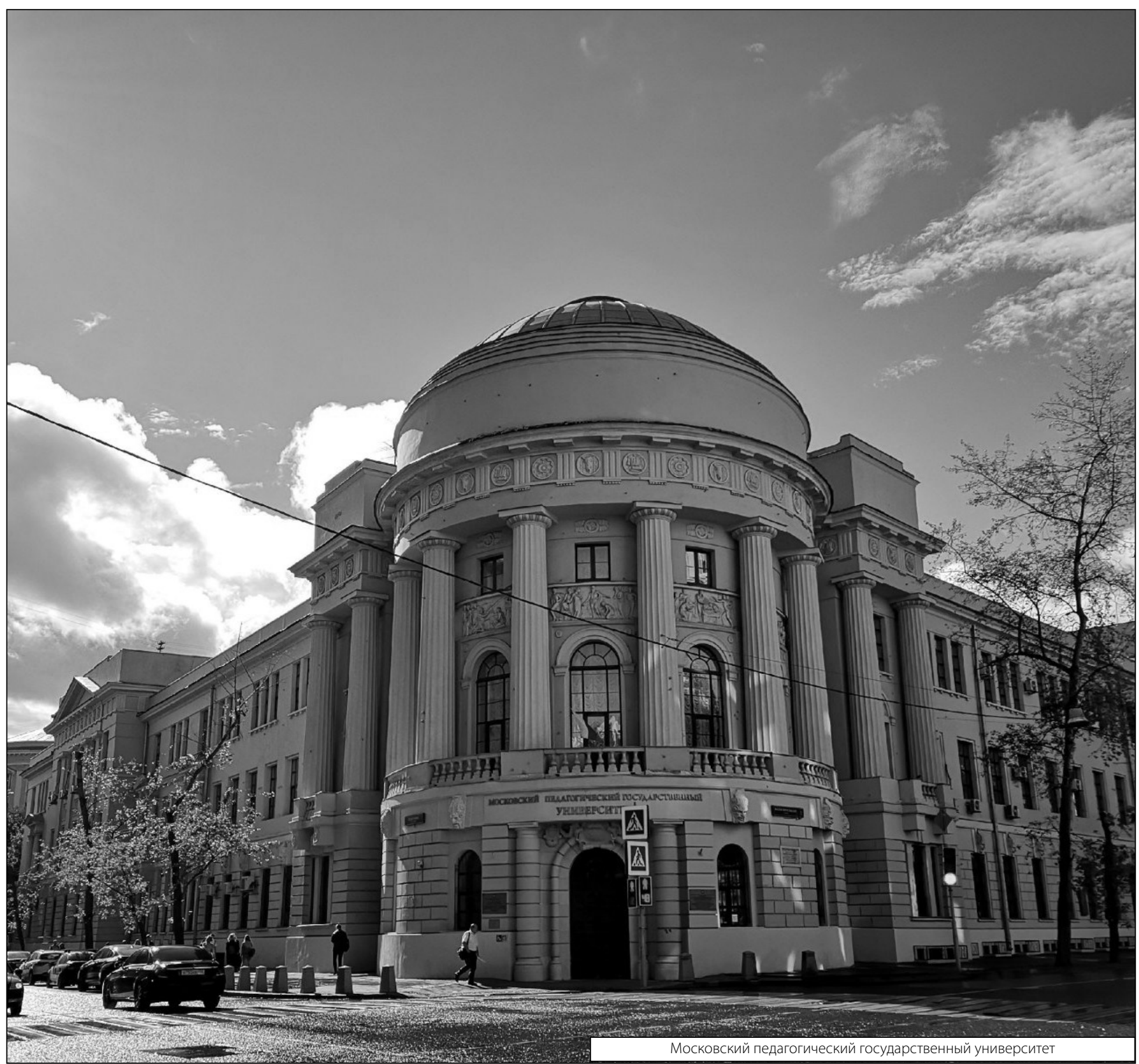

